\title{
COMPARISON OF MitochondRial DNA IN Wolves and CoYotes IN THE NORTHERN Rockies using the Polymerase Chain Reaction Technique
}

\author{
ERNEST R. VYSE \\ Department of Biology $\downarrow$ Montana State University \\ BOZEMAN
}

\section{$\downarrow \quad$ INTRODUCTION}

Conservation of biological species, often involves the introduction of organisms from one population to a site in which a population has gone locally extinct. The genetic constitution of the introduced organisms is of immediate concern both in terms of restoring the original population as nearly as possible and to maintain genetic diversity of the introduced organisms. Molecular techniques using protein or isozyme variation and DNA Restriction Fragment Length Polymorphisms (RFLPs), have been used to estimate genetic variation. These techniques are not sensitive enough to make comparisons using limited sample sizes or to analyze samples from preserved specimens of extinct organisms. The advent of the Polymerase Chain Reaction (PCR) (Saiki et al. 1985, 1988) which amplifies small segments of DNA millions of times has extended the application of molecular biology techniques to the genetic comparisons of dried or alcohol preserved museum specimens to extant organisms (Paabo 1989 and Paabo et al. 1989). Application of this technique has allowed the comparison of extinct organisms to each other and to extant species (Thomas et al. 1990).
PCR synthesizes many copies of the target sequence greatly increasing the quantity of the amplified sequence. PCR involves denaturing or strand separation of the DNA, hybridization of primers to the denatured single strands and then enzymatic extension of the primers using strands of the sample DNA as a template. This cycle is repeated many times, theoretically amplyfying the target DNA twofold with each cycle. Therefore, after $\mathrm{n}$ cycles there is 2 to the nth power as much of the target sequence DNA as there was in the original sample. Essentials of the PCR technique are shown in Figures 1 and 2 taken from Arnheim et al. (1990).

\section{$\downarrow \quad$ Materials ANd Methods}

Samples of wolf (Canis lupus) tissue were obtained from wolves killed on the Blackfoot Indian Reservation in Northern Montana and supplied by Montana Fish and Game. Coyote (Canis latrans) muscle and blood samples from YNP were provided by R. Crabtree and dried hide samples of wolves killed in the early 1900 s were supplied by R. D. Fisher from the National Museum of Natural History. 
DNA was extracted using standard techniques for tissue samples (Sambrook et al. 1989) or a modification developed by Allan Wilson's lab at the University of California, Berkley (Paabo et al. 1989) for dried skin tissues.

PCR was performed using Amplitag polymerase from Perkin Elmer Cetus in a reaction mix containing buffer (10 mM Tris-HC1 pH8.3, $2.5 \mathrm{mM} \mathrm{MgC1}{ }_{2}$ ), deoxynucleotide triphosphates (200 uM each dATP, dGTP, dCTP, dTTP), primers (synthesized oligonucleotides 20-30 nucleotides long designed to hybridize to conserved mt DNA sequences) (.1- 1.0 $\mathrm{uM}$ ), and Amplitaq polymerase (2-2.5U). PCR was performed in a Coy thermocycler at a denaturing temp of $92-94^{\circ} \mathrm{C}$ for one minute, hybridization temp. of $45^{\circ}$
$\mathrm{C}$ for 2 minutes and a chain elongation temp of $72^{\circ} \mathrm{C}$ for one minute. The cycle of denaturation, hybridization and elongation was repeated 40 times. PCR products were analyzed by electrophoreses in $1.2-2 \%$ agarose gels at $25-30 \mathrm{~mA}$ for $1-2 \mathrm{hrs}$.

Primers for PCR were synthesized in the Veterinary Molecular Biology Lab at Montana State University based on conserved sequences of the human mt DNA genome (Kocher et al. 1989) that have been shown to have wide applicability in vertebrates. Primers are designated with $\mathrm{L}$ or $\mathrm{H}$ which signifies the $\mathrm{L}$ or $\mathrm{H}$, strand in human mt DNA and the nucleotide number to which the 3 ' nucleotide in the primer corresponds to in human mt DNA.

12s ribosomalsomal

5'AAACTGGGATTAGATACCCCACTAT 3' L1067

5'GAGGGTGACGGGCGGTGTGT 3' H1478

D Loop 5' TCAAAGCTTACACCAGTCTTGTAAACC 3' L15926

5' TAACTGCAGAAGGCTAGGACCAAACCT 3' HOO651

5' GCGAATTCCTAGTGGGTGAGGGGTGGC 3' H16255

5' GCTCTAGACCATGCTTACAAGCAAGT 3' L16209

Cytochrome B 5' AAAAAGCTTCCATCCAACATCTCAGCATGATGAAA 3' L14841

5' AAACTGCAGCCCCTCAGAATGATATTTGTCCTCA 3' H15149

\author{
Cytochrome C oxidase 5'ATGCTAAGTTAGCTTTACAG 3' H8297 \\ 5'ATTCCCCTAAAAACTTTGA 3' L8244 \\ 5'ACAGTTTCATGCCCATCGTC 3' L8215
}

\section{$\downarrow \quad$ Results}

Amplification of DNA from wolf and coyote samples has been accomplished using all of the primers above except the cytochrome oxidase primers. Amplification of the cytochrome B fragment using PCR primers L14841 and H 15149 with both wolf and coyote samples is shown in Figure 3. Dilutions of one coyote sample from $1 / 10$ to $1 / 5000$ of the original extract still allows amplification of the cytochrome B fragment (Figure 4). The amount of amplified DNA in the $1 / 5000$ dilution suggests that this extract could still be diluted further and amplification of up to 10,000 fold has been achieved with other samples and primers. Unfortunately single stranded amplifications as a precursor to sequencing for species and individual comparisons has not yet been accomplished. The amplified products for both wolves and coyotes are the same approximate length based on the agarose gels but these gels are not capable of resolving small length differences and large differences between these closely related species is not expected. For species and individual comparisons, sequencing will be necessary. Although we are using published methods (McCabe 1989), these have not yet been fruitful. We are trying to improve single stranded amplifications, but if we are not successful, we will develop an alternative strategy for sequencing. This will be by sequencing the double stranded product or cloning the products into the M13 bacteriophage for sequencing. 


\section{Summary}

Mitochondrial (mt) DNA comparisons of wolves, coyotes and extinct Yellowstone National Park (YNP) wolves with the polymerse chain reaction (PCR) technique was begun in July 1990. Total cellular DNA was extracted from muscle samples of wolves killed near Glacier National Park in 1988 and stored at $-50^{\circ} \mathrm{C}$ along with muscle samples of coyotes killed in YNP in 1990. PCR reactions on these samples amplified DNA from the D loop, 12s ribosomal RNA gene, and cytochrome B gene of the mt DNA. Attempts to amplify DNA in the cytochrome oxidase gene has not been successful. Samples for the amplification of DNA extracted from YNP dried wolf skins shot in the early 1900 s was kindly supplied by R. D. Fisher of the National Museum of Natural History. In anticipation of amplifying DNA from these dried specimens we have amplified DNA extracted from muscle and diluted 5,000 and 10,000 times to demonstrate that we can still produce a product that is visible on an ethidium bromide agarose gel. We are currently attempting asymmetric PCR in anticipation of sequencing the PCR fragments for DNA comparisons between species and among individuals. To date, this necessary next step in the project has not been successful.

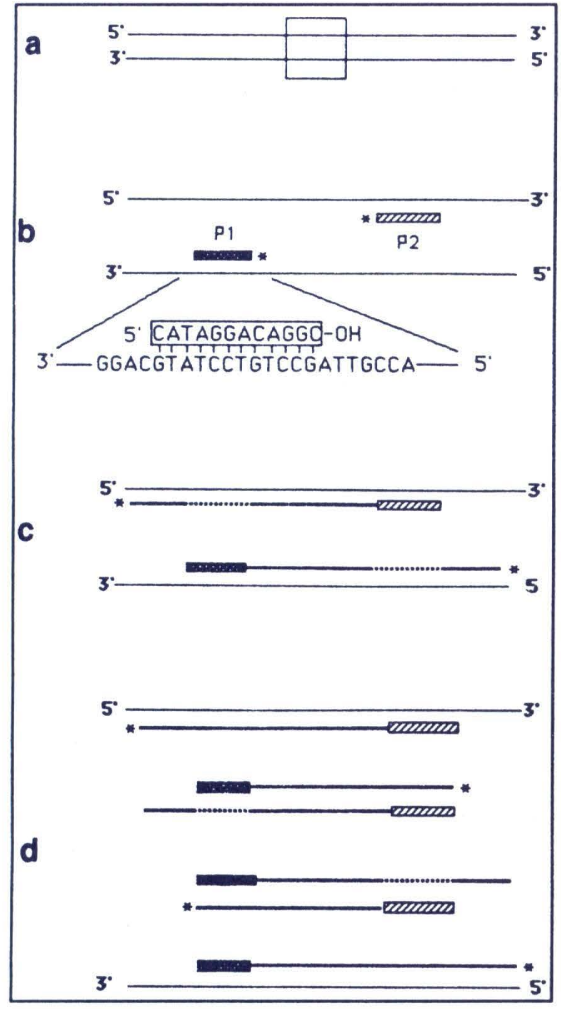

Figure 2. a. Temperature profile of three consecutive PCR cycles. Each cycle takes approximately three minutes. A typical experiment uses $95^{\circ} \mathrm{C}$ for denaturation. $54^{\circ} \mathrm{C}$ for primer annealing, and $72^{\circ} \mathrm{C}$ for polymerization.

b. Exponential increase of amplified product. The amount of product is shown as a function of the cycle number. The $3^{\prime}$ end of the fragment being elongated is marked with an asterisk. If every target molecule in a reaction is extended each cycle, then the amount of target will double each cycle. Under these conditions, 20 cycles increases the amount of target approximately $a$ millionfold. If only $90 \%$ of the targets get extended each cycle, 20 cycles yields a 375,000-fold amplification.
Figure 1. Principle of the polymerase chain reaction.

a. The target sequence within a double-stranded DNA molecule is indicated with a box.

b. After the DNA has been denatured, the two PCR primers, $P 1$ and $P 2$, anneal to the sequences flanking the target. The $3^{\prime}$ end of the primer undergoing elongation by DNA polymerase is denoted by . extension product complementary to the other primer is shown by a broken line.

d. In the second cycle of PCR, each of the four DNA strands shown in $c$ anneals to a primer, which is subsequently extended. Note that, at the completion of the second cycle, there are four doublestranded copies of the target, which was originally present as one double-stranded molecule in a. Note also that two of the eight single-stranded products are equal in length to the two primers and the intervening target. Products of this size accumulate exponentially during additional cycles.

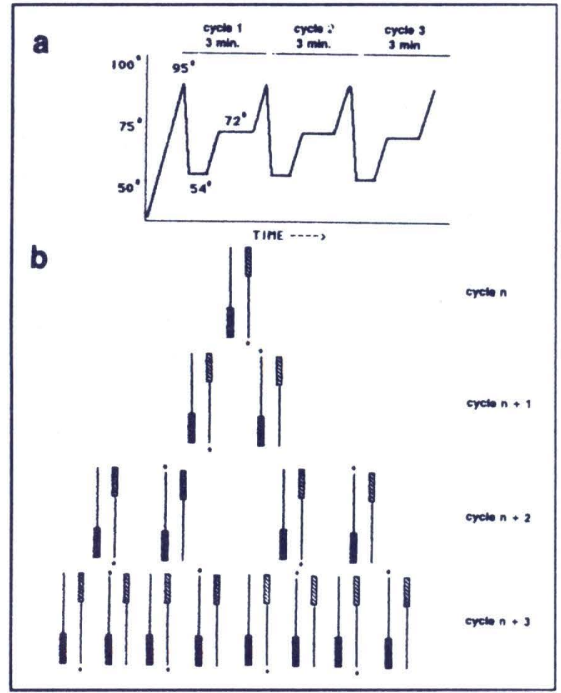




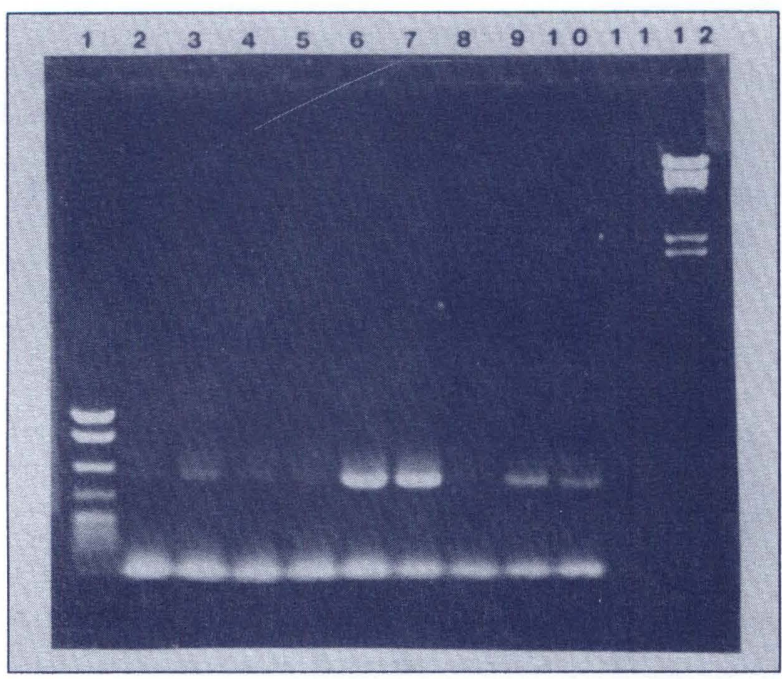

Figure 3. Amplified cytochrome B DNA fragments from wolf and coyote samples were electrophoresed in 1.2\% agarose gels at 25-30 MA for 1.5-2 hrs. and stained with ethidium bromide. Lane 1: Size marker pBR322 digested with Msp I (top five bands are 622, 527, 404, 309, and 242 bp), lane 2-5: wolves, lanes 6-10: coyotes, lane 11: negative control, lane 12: Size marker lambda DNA digested with Hind III

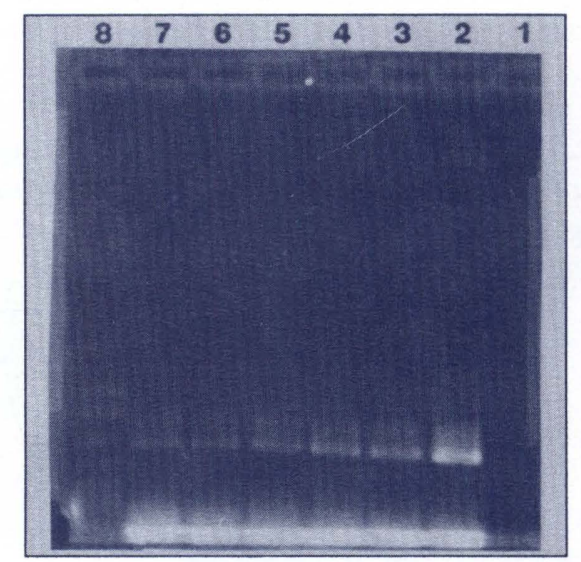

Figure 4. DNA extracted from coyote muscle was diluted and then amplified by $P C R$ using the cytochrome B primers. Reactions $(20 \mathrm{ul})$ were analyzed by electrophoresis as in figure 3. Lane 1: Negative control, lanes 2-7: dilutions 1/10, 1/100, $1 / 200,1 / 500,1 / 1000,1 / 5000$, lane 8: pBR322 size marker as in figure 3.

\section{Literature Cited}

Arnheim, N., T. White, and W. E. Rainey. 1990. Application of PCR: Organismal and Population Biology. BioScience 40:174-182.

Kocker, T., W. K. Thomas, A. Meyer, S. V. Edwards, S. Paabo, F. X. Villabanca and A. C. Wilson. 1989. Dynamics of mitochondrial DNA evolution in animals: Amplification and sequencing with conserved primers. Proc. Nat'l. Aca. Sci. 86:6196-6200.

McCabe, P. C. 1989. Asymmetric Polymerase Chain Reaction. Amplifications (A Perkin Elmer Cetus publication) pages 1-3.

Paabo, S. 1989. Ancient DNA: Extraction, characterization, molecular cloning, and enzymatic amplification. Proc. Nat'l. Acad. Sci. 86:1939-1943.

Paabo, S., R. C. Higuichi and A. C. Wilson. 1989. Ancient DNA and the Polymerase Chain Reaction. J. Biol. Chem. 9709-9712.

Saiki, R. K., S. Scharf, F. Faloona, K. B. Mullis, G. T. Horn, H. A. Erlich, and N. Arnheim. 1985. Enzymatic amplification of B-globin genomic sequences and restriction site analysis for diagnosis of sickle cell anemia. Science 230:1350-1354.

Saiki, R. K., D. H. Gelfand, S. Stoffel, R. Higuchi, G. T. Horn, K. B. Mullis and H. A. Erlich. 1988. Primer directed enzymatic amplification of DNA with a thermostable DNA polymerase. Science 239:487-491.

Sambrook, J. E., F. Fritsch and T. Maniatis. 1989. Molecular Cloning: A laboratory manual. Three volumes. Cold Spring Harbor Laboratory Press.

Thomas, W. K., S. Paabo, F. X. Villablanca and A. C. Wilson. 1990. Spatial and temporal continuity of kangaroo rat populations shown by sequencing mitochondrial DNA from museum specimens. J. Mol. Evol. 31:101-112. 